\title{
Differences between young adults and elderly in thermal comfort, productivity, and thermal physiology in response to a moderate temperature drift and a steady-state condition.
}

Citation for published version (APA):

Schellen, L., van Marken Lichtenbelt, W. D., Loomans, M. G., Toftum, J., \& de Wit, M. H. (2010). Differences between young adults and elderly in thermal comfort, productivity, and thermal physiology in response to a moderate temperature drift and a steady-state condition. Indoor Air, 20, 273-283. https://doi.org/10.1111/j.1600-0668.2010.00657.x

Document status and date:

Published: 01/01/2010

DOI:

10.1111/j.1600-0668.2010.00657.x

Document Version:

Publisher's PDF, also known as Version of record

Document license:

Taverne

Please check the document version of this publication:

- A submitted manuscript is the version of the article upon submission and before peer-review. There can be important differences between the submitted version and the official published version of record. People interested in the research are advised to contact the author for the final version of the publication, or visit the DOI to the publisher's website.

- The final author version and the galley proof are versions of the publication after peer review.

- The final published version features the final layout of the paper including the volume, issue and page numbers.

Link to publication

\footnotetext{
General rights rights.

- You may freely distribute the URL identifying the publication in the public portal. please follow below link for the End User Agreement:

www.umlib.nl/taverne-license

Take down policy

If you believe that this document breaches copyright please contact us at:

repository@maastrichtuniversity.nl

providing details and we will investigate your claim.
}

Copyright and moral rights for the publications made accessible in the public portal are retained by the authors and/or other copyright owners and it is a condition of accessing publications that users recognise and abide by the legal requirements associated with these

- Users may download and print one copy of any publication from the public portal for the purpose of private study or research.

- You may not further distribute the material or use it for any profit-making activity or commercial gain

If the publication is distributed under the terms of Article 25fa of the Dutch Copyright Act, indicated by the "Taverne" license above, 


\section{Review Article}

\section{Differences between young adults and elderly in thermal comfort, productivity, and thermal physiology in response to a moderate temperature drift and a steady-state condition}

\begin{abstract}
Results from naturally ventilated buildings show that allowing the indoor temperature to drift does not necessarily result in thermal discomfort and may allow for a reduction in energy use. However, for stationary conditions, several studies indicate that the thermal neutral temperature and optimum thermal condition differ between young adults and elderly. There is a lack of studies that describe the effect of aging on thermal comfort and productivity during a moderate temperature drift. In this study, the effect of a moderate temperature drift on physiological responses, thermal comfort, and productivity of eight young adults (age 22-25 year) and eight older subjects (age 67-73 year) was investigated. They were exposed to two different conditions: $\mathrm{S} 1$-a control condition; constant temperature of $21.5^{\circ} \mathrm{C}$; duration: $8 \mathrm{~h}$; and $\mathrm{S} 2-\mathrm{a}$ transient condition; temperature range: $17-25^{\circ} \mathrm{C}$, duration: $8 \mathrm{~h}$, temperature drift: first $4 \mathrm{~h}:+2 \mathrm{~K} / \mathrm{h}$, last $4 \mathrm{~h}:-2 \mathrm{~K} / \mathrm{h}$. The results indicate that thermal sensation of the elderly was, in general, 0.5 scale units lower in comparison with their younger counterparts. Furthermore, the elderly showed more distal vasoconstriction during both conditions. Nevertheless, TS of the elderly was related to air temperature only, while TS of the younger adults also was related to skin temperature. During the constant temperature session, the elderly preferred a higher temperature in comparison with the young adults.
\end{abstract}

\section{Schellen ${ }^{1}$, W. D. van Marken Lichtenbelt ${ }^{2}$, M. G. L. C. Loomans ${ }^{3}$, J. Toftum ${ }^{4}$, M. H. de Wit $^{5}$}

${ }^{1}$ Eindhoven University of Technology, MB Eindhoven, The Netherlands, ${ }^{2}$ Maastricht University, MD

Maastricht, The Netherlands, ${ }^{3}$ Eindhoven University of Technology, MB Eindhoven, The Netherlands,

${ }^{4}$ Technical University of Denmark, Lyngby, Denmark, ${ }^{5}$ Eindhoven University of Technology, MB Eindhoven, The Netherlands

Key words: Thermal comfort; Aging; Moderate temperature drift; Physiological responses; Productivity.

L. Schellen

Eindhoven University of Technology

P.0. Box 513, 5600 MB Eindhoven

The Netherlands

Fax: +31-40-243-8595

e-mail: L.Schellen@tue.nl

Received for review 2 October 2009. Accepted for publication 12 April 2010.

\section{Practical Implications}

Because the stock of fossil fuels is limited, energy savings play an important role. Thermal comfort is one of the most important performance indicators to successfully apply measures to reduce the energy need in buildings. Allowing drifts in indoor temperature is one of the options to reduce the energy demand. This study contributes to the knowledge concerning the effects of a moderate temperature drift and the age of the inhabitants on their thermal comfort.

\section{Introduction}

Both thermal comfort and energy use play an important role in the performance of a building. Approximately one-third of the primary energy used in developed countries is consumed by heating, ventilating, and air-conditioning in residential, commercial, and public buildings (IEA, 2007). Given these energy requirements, it is relevant to study how energy savings can be achieved together with acceptable thermal comfort and performance.

Results from naturally ventilated buildings in practice revealed that satisfaction with the thermal environment does not mean that this environment has to be controlled at a constant indoor air temperature (de Dear and Brager, 1998 and 2001; Olesen and Parsons, 2002; Olesen, 2004). Compared to a constant temperature, allowing the temperature to drift could be a means to reduce energy use.

In the past, several studies have been conducted to examine the influence of a temperature drift and a wider temperature range on thermal comfort and performance. These studies show that temperature drifts can be acceptable in air-conditioned buildings without selfcontrol. The results of these studies show that slow temperature ramps up to $0.5 \mathrm{~K} / \mathrm{h}$ have no effect on the 
width of the comfort zone as established under steadystate conditions; the environment is experienced as in steady-state conditions, i.e. slow temperature ramps $(0.5 \mathrm{~K} / \mathrm{h})$ were not significantly noticeable to the occupants (Berglund and Gonzalez, 1978a,b; Griffiths and McIntyre, 1974; Rohles et al., 1985). Berglund and Gonzalez also stated that at fast temperature changes $(1.0$ and $1.5 \mathrm{~K} / \mathrm{h})$, the allowable deviation from the optimum thermal condition was larger in comparison with slow temperature changes $(0.5 \mathrm{~K} / \mathrm{h})$.

Hensen (1990) and Kolarik et al. (2005) concluded from their reviews that for rates between 0.5 and 1.5 $\mathrm{K} / \mathrm{h}$, there is no clear evidence of increased or decreased comfort zones owing to temperature drifts, except from experiments with uncommon acceptability assessment procedures. From these studies, it can be concluded that the knowledge regarding the effects of temperature drifts on human thermal comfort is still limited.

In a recent study by Kolarik et al. (2007), different operative temperature ramps $( \pm 0.6, \pm 1.2,+2.4$, $+4.8 \mathrm{~K} / \mathrm{h}$; temperature ranges: $22-26.8$ and $17.8-$ $25^{\circ} \mathrm{C}$ ) were investigated to determine the influence of the slope. They found that a slow temperature drift $( \pm 0.6 \mathrm{~K} / \mathrm{h}$ ) was perceived by the subjects with $3-4 \mathrm{~h}$ delay (depending on clothing level). During the first 3$4 \mathrm{~h}$ of exposure, subjects did not distinguish a slow temperature increase $(+0.6 \mathrm{~K} / \mathrm{h})$ from a constant temperature level $\left(21.4\right.$ and $\left.24.4^{\circ} \mathrm{C}\right)$. These results are in agreement with earlier mentioned studies by Berglund and Gonzalez (1978a,b) and Rohles et al. (1985).

The results also indicate that not the temperature ramp, but the combination of a temperature level above $24.4^{\circ} \mathrm{C}$ and the time of exposure affected the thermal sensation. Furthermore, a linear relation was found between mean thermal sensation and operative/ air temperature for all the studied ramps.

In the building design phase, it is useful to predict thermal comfort of the occupants; often, the PMV/ PPD model is used for this. However, Nicol and Humphreys (2002) showed, based on data of the ASHRAE RP-884 database (de Dear et al., 1997), that the PMV model might not be applicable to predict thermal comfort for conditions that deviate much from thermal neutral conditions.

Although the PMV model was developed for steadystate conditions, the study by Kolarik et al. (2007) indicates that the PMV model might also be applicable for transient conditions. For all slopes, the relation between instantaneous mean thermal sensation and prediction by the PMV model (ISO 7730, 2005) was in reasonably good agreement (Kolarik et al., 2007), which was found by Schellen et al. (2008) as well.

The same was found by Knudsen et al. (1989); they concluded that the PMV model possibly can be used for temperature ramps up to $\pm 5 \mathrm{~K} / \mathrm{h}$.

Seppänen and Fisk (2005) describe a literature review on the influence of temperature on performance.
Several types of office tasks were analyzed, including text typing and the duration of telephone calls during call center work. According to their analyses, no influence of room temperature was found between 20 and $25^{\circ} \mathrm{C}$. Above $25^{\circ} \mathrm{C}$, and below $20^{\circ} \mathrm{C}$, a decrease of $2 \% /{ }^{\circ} \mathrm{C}$ in performance was observed. These findings were confirmed in studies by Seppänen and Fisk (2005) and Tanabe (2006).

On the contrary, Toftum (2005) discovered a significant negative effect on performance when increasing the temperature from $20-22$ to $22-24^{\circ} \mathrm{C}$.

Studies concerning the effects of temperature drifts on performance and productivity were only found for studies comprising short cyclical temperature swings around the preferred ambient temperature. Kolarik et al. (2005) concluded that small rapid swings (4 K/ $8 \mathrm{~min}$ ) around the preferred temperature resulted in a decreased performance and work speed. Conversely, larger and slower swings ( $4 \mathrm{~K} / 32 \mathrm{~min}$ ) were related to a higher work speed in comparison with results achieved under steady-state conditions. The performance was equal to the performance achieved under steady-state conditions.

According to these findings, temperature transients can have a positive influence on the work speed (productivity) and perhaps performance, although thermal discomfort cannot be ruled out.

For both temperature and productivity, no studies are available to determine the effects of aging on thermal comfort and productivity during a moderate temperature drift. In this study, this effect has been investigated.

The above-mentioned studies reveal a challenge to explore whether faster $(> \pm 0.5 \mathrm{~K} / \mathrm{h})$ temperature drifts, both increasing and decreasing, are acceptable during a longer period of time in air-conditioned buildings.

Moreover, there exists a need to study thermal preferences of elderly and resulting requirements (van Hoof, 2008; van Hoof and Hensen, 2006).

ASHRAE (2009) states, based on research by among others Rohles and Johnson (1972), Fanger and Langkilde (1975) and Fanger (1982), that the thermal conditions preferred by elderly do not differ from those preferred by younger adults. This does not mean that the elderly and young adults are equally sensitive to cold or heat.

On the contrary, several studies indicate that the thermal neutral temperature and optimum thermal condition of elderly differ from the thermal neutral temperature and optimum condition of young adults, mainly because of an average lower activity level (which implies a lower metabolic heat production). Therefore, elderly might require a higher ambient temperature to achieve thermal comfort in comparison with younger adults at equal clothing levels (Cena et al., 1986; Collins et al., 1981; DeGroot and Kenny, 
2007; Hardy and Dubois, 1940; Hashiguchi et al., 2004; Havenith, 2001; van Hoof and Hensen, 2006; Natsume et al., 1992).

As, in the next 20 years, in the western world, the number of people aged 60 or older will increase from $15.4 \%$ in 1996 to $25.3 \%$ in 2030 (Howden-Chapman et al., 1999), it is relevant to study possible differences in thermal comfort, physiological responses, and performance between young and elderly people experiencing a moderate temperature drift.

Following the above, the objective of this work was to study differences in thermal comfort, physiological responses, and productivity between young and elderly people under a moderate temperature drift.

\section{Methods}

Design

The experiments were carried out in a climate room $\left(4.5 \times 3.7 \times 2.3 \mathrm{~m}^{3}, \mathrm{~L} \times \mathrm{W} \times \mathrm{H}\right)$ at the laboratory of the unit Building Physics and Systems at Eindhoven University of Technology (Figures 1 and 2), where air temperature and relative humidity could be controlled accurately. The climate room is situated in a laboratory with a controlled constant indoor climate. The room consists of well-insulated walls with a low thermal mass; therefore, the wall temperatures of the room followed the air temperature near instantly. The air, conditioned by an air-handling unit (Fischback Luftungs- und Klimatechnik GmbH, type VNM), was supplied through a high inductive outlet vent. To further increase the mixing of the air, a ceiling fan was installed, resulting in a mean air velocity near the

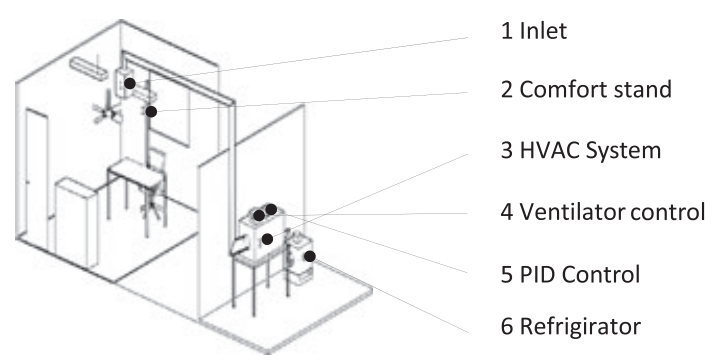

Fig. 1 Schematic representation of climate room

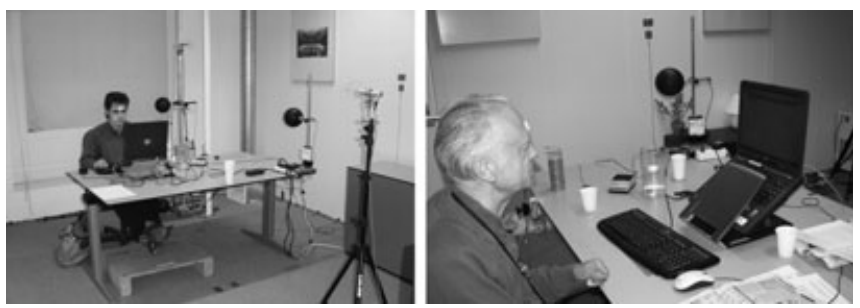

Fig. 2 Impression of test subjects in climate room subject of $0.19 \pm 0.03 \mathrm{~m} / \mathrm{s}$. The temperature of the supplied air was controlled through a PID controller (Temperature controller, West type 1600). The relative humidity $(\mathrm{RH})$ was controlled at a fixed level of nearly $40 \%(43.2 \pm 2.3 \%)$.

Sixteen subjects (eight young adults, age 22-25, and eight older adults, age 67-73) were recruited to participate in the experiment. All subjects were men, healthy, normotensive, and not taking any medications that might alter the cardiovascular or thermoregulatory responses to the temperature changes; subject characteristics per group are listed in Table 1.

Body fat percentage was determined by means of skinfold thickness, according the Siri equation (Durnin and Rahaman, 1967). Skin folds were measured at four sites: subscapular, suprailiacal, and at the triceps and biceps (Lohman et al., 1988).

The subjects visited the climate room on two occasions (S1 and S2) that differed in indoor climate conditions. The order of the conditions was alternated (e.g. subject 1 started with $\mathrm{S} 1$ and ended with S2, subject 2 started with S2 and ended with S1, subject three started with S1, etc.).

S1: A steady temperature $\left(21.5^{\circ} \mathrm{C}\right)$. Session $S 1$ (duration $8 \mathrm{~h}$ ) was the control situation; with the results of this session, possible time effects have been assessed. The temperature was fixed at $21.5^{\circ} \mathrm{C}\left(21.5 \pm 0.12^{\circ} \mathrm{C}\right)$, which corresponds to a neutral thermal sensation $(\mathrm{PMV} \approx 0)$.

S2: A transient condition. During session $S 2$, a moderate temperature ramp (duration: $8 \mathrm{~h}$; temperature range: $17-25^{\circ} \mathrm{C}$; temperature drift: first $4 \mathrm{~h}$ : $+2 \mathrm{~K} / \mathrm{h}$, last $4 \mathrm{~h}$ : $-2 \mathrm{~K} / \mathrm{h}$ ) was imposed. Through this course, both the effects of an increasing and decreasing ramp could be evaluated.

Most of the experiments conducted in the past focused on the effects of temperatures warmer than neutral. In this study, temperatures colder than neutral will be studied as well. The minimum temperature of $17^{\circ} \mathrm{C}$ was set to avoid shivering, and therefore, it is assumed that the condition will not be unacceptable cold (Parsons, 2003). The maximum temperature of $25^{\circ} \mathrm{C}$ fits within the comfort zone $(\mathrm{PMV}<0.5)$ according to ASHRAE (2004) and ISO 7730 (2005). The imposed drift of $2 \mathrm{~K} / \mathrm{h}$ is within the comfort limit (ISO 7730, 2005).

Table 1 Subject characteristics per age group

\begin{tabular}{lllll}
\hline & Age (year) & Height* $(\mathrm{m})$ & Weight $^{*}(\mathrm{~kg})$ & Body fat\%* $(\%)$ \\
\hline Young adults & $22-25$ & $1.83 \pm 0.11$ & $82.7 \pm 8.6$ & $14.5 \pm 3.3$ \\
Older adults & $67-73$ & $1.76 \pm 0.06$ & $77.8 \pm 7.2$ & $18.7 \pm 5.3$
\end{tabular}

*Mean \pm SD. 


\section{Schellen et al.}

Furthermore, this drift represents a building warming up during the beginning of the day and cooling down during the second part of the day when the heating is turned off. It was assumed that cooling down the temperature in the second part of the day could perhaps positively influence the productivity owing to 'freshness of mind'.

The applied temperature course is represented in Figure 3. Mean deviation from the desired temperature course was $0.08 \pm 0.49^{\circ} \mathrm{C}$.

Prior to the measurements, the subjects performed a light exercise until skin vasodilatation occurred to ensure all subjects entered the climate room in an equal thermal state. Vasodilatation was assessed by the skin temperature difference between forearm and top of the forefinger (House and Tipton, 2002; Sessler, 2003). After entering the climate room, the experiment started with an acclimatization period (30 min). During this period, the skin temperature sensors were attached, and their characteristics (height, weight, and fat percentage) were determined. Furthermore, they received an instruction regarding the use of the questionnaires. During the experiments, the subjects wore standardized clothing, consisting of a cardigan, jogging pants, thin T-shirt, underpants, and socks and shoes. The clovalues were determined according to ISO 9920 (1995) and the database of McCullough et al. (1989, 1994). The total heat resistance of the clothing ensemble, including desk chair, was approximately 1.0 clo.

The subjects continuously performed office tasks; their metabolic rate was estimated to be approximately 1.2 met (ISO 7730, 2005).

The volunteers were given detailed information regarding the purpose and the methods used in the study, before written consent was obtained.

\section{Measurements}

During the experiments, both physical and physiological measurements were carried out continuously. The measurements of the environmental parameters, air temperature (NTC Thermistor, type SC95), relative humidity (RH) (Humidity Sensors, Honeywell HIH-
4000 series), air velocity (hot sphere anemometer, Dantec), mean radiant temperate (black bulb $0.15 \mathrm{~m}$ ), carbon dioxide (Carbon Dioxide Transmitter, Vaisala 0-2000 ppm), and illuminance (Lux meter, Hager model E2) were taken according to ISO 7726 (1998). Air temperature, $\mathrm{RH}$, and air velocity were measured on a comfort stand at $0.1,0.6,1.1$ and $1.7 \mathrm{~m}$ height.

The skin temperatures were measured according to ISO 9886 (2004) by wireless iButtons (Thermochron iButton ${ }^{\circledR}$ DS1291H, Dallas Maxim) at 17 locations (van Marken Lichtenbelt et al., 2006).

Mean skin temperature was calculated on the basis of the 14-point weighing as proposed by ISO 9886 (2004).

The distal skin temperature was calculated as average of the finger tip, instep, hand, and forehead skin temperature. To avoid a disproportional distribution, finger tip and hand temperatures were averaged. The proximal skin temperature was calculated as an average of the scapula, paravertebral, upper chest, and abdomen skin temperature. To obtain more insight into the extent of vasomotion (vasoconstriction and vasodilatation), three measurement sites were added: top of the middle right toe, left forearm, and top of left forefinger.

The core temperature was measured rectally at $10-15 \mathrm{~cm}$ deep in the young subjects (thermistor-probe, NTC Thermistor type SC95). In the elderly, the core temperature was determined by measuring the intestinal temperature through an ingestible telemetry pill (CorTemp ${ }^{\mathrm{TM}}$, Ingestible Core Body Temperature Sensor, HT150002, HQ Inc., Palmetto, FL, USA), which was ingested $30 \mathrm{~min}$ before entering the climate room.

\section{Questionnaires}

Two times per hour, the test subjects filled in a questionnaire that included a continuous 7-point thermal sensation interval scale (ISO 7730, 2005), scales to assess the acceptability of the thermal environment, and visual analog scales (VAS) to assess adverse perceptions and the perceived indoor environment (Kildesø et al., 1999). A questionnaire to assess

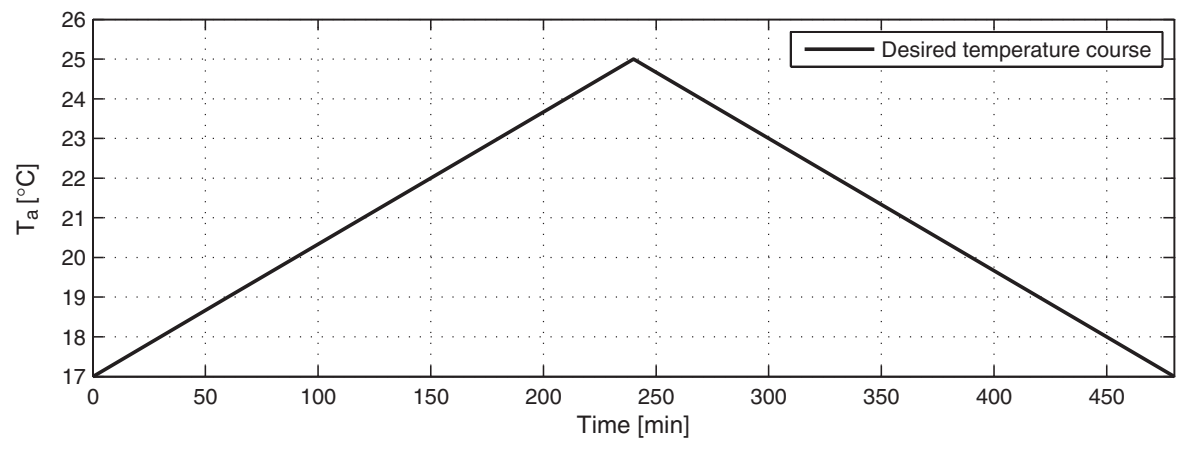

Fig. 3 Designed temperature course condition S2 
self-estimated performance and a questionnaire to assess perceived stress were included as well. To assess the performance, a 'Remote Performance Measurement' (RPM) method was used (Toftum et al., 2005). Within this method, the performance was estimated by two simulated office tasks: text typing and addition.

Both questionnaires and office tasks were presented in Dutch to the subjects through an Internet browser.

The differences in physiological responses, subjective responses, and performance were studied using ANOVA and a linear mixed effects model (LME) treating subject as a random factor; the experimental conditions were analyzed separately in the ANOVA model. To assess explaining variables for the thermal sensation and thermal comfort of the subject, stepwise linear regression was used. Significant effects are reported for $P<0.05$. Two statistical software packages were used to analyze the data; for the LME analyses, the free-available R 2.9.2 (R Foundation for Statistical Computing, Vienna, Austria) software package was used; for all other analyses, the commercially available software package SPSS 16.0 (SPSS Inc., Chicago, USA) was used.

\section{Results}

Physiological measurements

Mean, distal, and proximal skin temperatures and core temperature of young (Y) and elderly (E) subjects for both sessions (S1 and S2) are given in Figure 4.
For all three different skin temperatures, the difference between young and elderly was significant $(P<0.01)$. The majority of the local skin temperatures (forehead, neck, scapula, upper chest, upper arm, hand, abdomen, paravertebral, shin, calf, and instep) of the elderly were significantly lower than the skin temperature of the young adults. The temperature of the fingertip showed the largest difference, $29.1 \pm 1.90^{\circ} \mathrm{C}[\mathrm{S} 1]$ and $27.5 \pm 2.76^{\circ} \mathrm{C}$ [S2] for the young adults vs. $24.8 \pm 2.73^{\circ} \mathrm{C} \quad[\mathrm{S} 1]$ and $24.9 \pm 2.12^{\circ} \mathrm{C}[\mathrm{S} 2]$ for the elderly. However, three measurement locations showed a deviation. At the underarm, the difference was not significant; at the front and back of the upper leg (anterior and posterior thigh), the skin temperature of the elderly was for both sessions significantly $(P<0.001)$ higher than of the young adults, although this difference was comparatively small $\left(<0.8^{\circ} \mathrm{C}\right)$.

The mean core temperatures of the elderly $\left(36.6 \pm 0.27^{\circ} \mathrm{C}[\mathrm{S} 1]\right.$ and $\left.36.5 \pm 0.33^{\circ} \mathrm{C}[\mathrm{S} 2]\right)$ were significantly lower compared to their younger counterparts: $\left(37.0 \pm 0.08^{\circ} \mathrm{C}[\mathrm{S} 1]\right.$ and $\left.36.9 \pm 0.09^{\circ} \mathrm{C}[\mathrm{S} 2]\right)$. Possibly, this difference is caused by the difference in measuring technique for Tcore between the groups.

The difference (gradient) between fingertip and forearm temperature is given in Figure 5. Positive values indicate vasoconstriction (forearm temperature is higher than finger tip temperature), while negative values indicate vasodilatation. The fingertip-underarm gradient of the young adults is smaller during both sessions in comparison with the elderly, which is caused
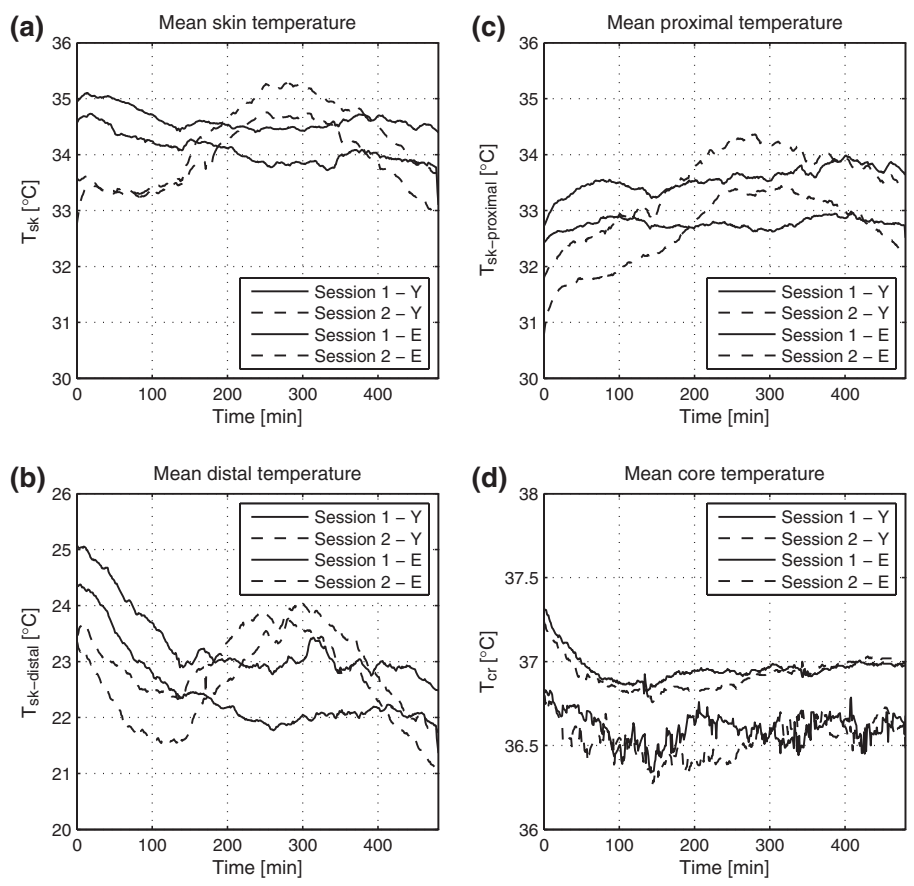

Fig. 4 Mean (a), distal (b), and proximal (c) skin temperatures and core temperature (d) of young and elderly subjects during both experimental conditions 


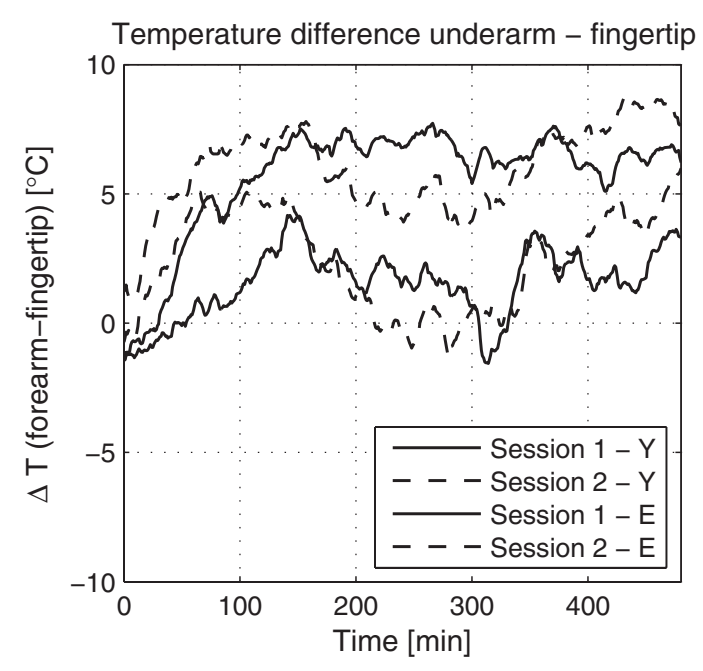

Fig. 5 Mean difference between forearm and fingertip temperature of young and elderly subjects during both experimental conditions

by the differences in vasoconstriction between the young adults and the elderly. Furthermore, the results of the young adults show a slightly negative difference (vasodilatation) as result of the high temperatures during session 2, in contrast to the elderly who maintained finger skin vasoconstriction.

The drop in distal skin temperatures during approximately the first $100 \mathrm{~min}$ of both conditions (S1 and S2) is most probably caused because the subjects started the experiment in vasodilatation state $\left(\Delta T_{\text {(forearm-fingertip) }}\right.$ $\approx 0$ ), which was maintained during the acclimatization period owing to the slightly elevated activity level. After the start of the experiment $(t=0)$, the subjects were completely sedentary, which resulted in a slight decrease in core temperature (Figure 4d) caused by a lowered internal heat production (metabolism). To maintain core temperature constant, vasoconstriction was activated, indicated by the increase in forearmfingertip gradient (Figure 5) and drop in distal temperatures (Figure $4 b$ ).

\section{Subjective responses}

The results of the questionnaires have been analyzed separately for both experimental conditions ( $\mathrm{S} 1$ and S2) and for both parts of the condition (1: first $4 \mathrm{~h}, 2$ : last $4 \mathrm{~h}$ ) to be able to distinguish between a constant temperature and a temperature drift and to analyze time effects.

Thermal sensation (TS) of the young adults was significantly (ANOVA, $P<0.001$ ) affected by the two different conditions (Figure 6a). In the design of the experiment, the temperature of session S1 was determined to be equal to a neutral thermal sensation according the PMV model (ISO 7730, 2005). Averaged TS for the young subjects was $-0.18 \pm 0.56$ during
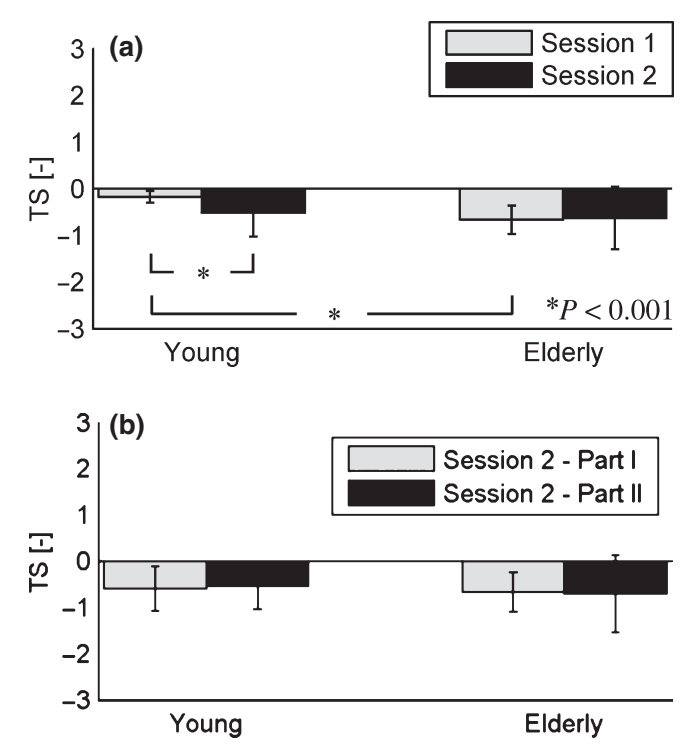

Fig. 6 (a) Mean thermal sensation (TS) \pm SD per measurement session (-3: Cold, -2: Cool, -1: Slightly Cool, 0: Neutral, 1: Slightly Warm, 2: Warm, 3 Hot) (b) Mean thermal sensation; Part 1: first $4 \mathrm{~h}$ of session 2; Part 2: last $4 \mathrm{~h}$ of session 2

session $\mathrm{S} 1$ and $-0.52 \pm 0.76$ during session $\mathrm{S} 2$. TS of the elderly was $-0.67 \pm 0.66$ and $-0.63 \pm 0.93$, respectively.

TS during session $\mathrm{S} 2$ is not influenced by time. Differences (insignificant, $P>0.05$ ) between first and last part of session S2 are represented in Figure 6 b.

In Table 2, the results of stepwise multiple regression analysis are represented for thermal sensation as independent variable for the young adults and the elderly, respectively, only significant variables are listed. The following variables were taken into account as possible predictive variables: mean air temperature, mean, proximal, and distal skin temperature, mean air velocity, fingertip-underarm gradient, core temperature, and the change in mean skin temperature.

In Table 3 , the significant $(P<0.05)$ explaining variables per part (I and II) of the measurement session according to stepwise linear regression analyses are

Table 2 Results from stepwise multiple regression model with (a) $T_{\mathrm{a}}, T_{\text {core }}$ and $T_{\text {skin }}$ as predictive variables for young subjects (b) $T_{\mathrm{a}}, T_{\text {core }}$ and $\Delta T_{\text {(forearm-fingertip) }}$ as predictive variables for elderly subjects and thermal sensation as the dependent variable

\begin{tabular}{lrll}
\hline Independent variables & Slope & Significance $(P)$ & $R_{\text {adj }}^{2}$ \\
\hline (a) & & & \\
Air temperature $\left(T_{\mathrm{a}}\right)$ & 0.215 & $0.000^{*}$ & 0.34 \\
Core temperature $\left(T_{\text {core }}\right)$ & 0.646 & $0.000^{*}$ & \\
Mean skin temperature $\left(T_{\text {sk }}\right)$ & 0.177 & $0.005^{*}$ & \\
(b) & & & \\
Air temperature $\left(T_{\mathrm{a}}\right)$ & 0.221 & $0.000^{*}$ & \\
Vasomotion $\left(\Delta T_{\text {(forearm-fingertip) }}\right.$ & -0.087 & $0.000^{*}$ & \\
Core temperature $\left(T_{\text {core }}\right)$ & -0.299 & $0.018^{*}$ & \\
& & &
\end{tabular}

${ }^{*}$ Significant $(P<0.05)$. 
Differences between young adults and elderly in thermal comfort, productivity, and thermal physiology

Table 3 Explaining variables for thermal sensation as independent variable

\begin{tabular}{|c|c|c|c|c|}
\hline & \multicolumn{2}{|l|}{ Session 1} & \multicolumn{2}{|l|}{ Session 2} \\
\hline & Part I & Part II & Part I & Part II \\
\hline Young adults & $\begin{array}{l}\text { Core temperature }\left(T_{\mathrm{cr}}\right) \text {; Distal } \\
\text { skin temperature }\left(T_{\text {sk;dist }}\right) \text {; Proximal skin } \\
\text { temperature }\left(T_{\text {sk; prox }}\right) \text {; Extent of } \\
\text { vasomotion }\left(\Delta T_{\text {forearm-fingertip }}\right)\end{array}$ & - & $\begin{array}{l}\text { Air temperature }\left(T_{\mathrm{a}}\right) \text {; Core temperature }\left(T_{\mathrm{cr}}\right) \text {; } \\
\text { Distal skin temperature }\left(T_{\mathrm{sk} ; \text { dist }}\right)\end{array}$ & $\begin{array}{l}\text { Air temperature }\left(T_{\mathrm{a}}\right)_{i} \\
\text { Mean skin temperature }\left(T_{\mathrm{sk}}\right)\end{array}$ \\
\hline Older adults & Proximal skin temperature $\left(T_{\text {sk;prox }}\right)$ & $\begin{array}{l}\text { Mean skin temperature }\left(T_{\text {sk }}\right) \text {; } \\
\text { Extent of vasomotion } \\
\left(\Delta T_{\text {forearm-fingertip }}\right) ; \\
\text { Core temperature }\left(T_{\text {core }}\right)\end{array}$ & $\begin{array}{l}\text { Air temperature }\left(T_{\mathrm{a}}\right) ; \\
\text { Extent of vasomotion }\left(\Delta T_{\text {forearm-fingertip }}\right)\end{array}$ & Air temperature $\left(T_{\mathrm{a}}\right)$ \\
\hline
\end{tabular}

listed. No possible effects of time on TS could be observed.

Linear regression analyses of TS as dependent variable and $T_{\mathrm{a}}$ as independent variable show the difference in TS between the young and older adults. Generally, TS of the older adults is approximately 0.5 lower than TS of the younger adults (Figure 7). However, only for session S1, the differences are significant (LMM, $P<0.05$ ). Comparing the subjective votes for TS and predicted votes according the PMV model, a similar trend can be detected; the general trend is in good agreement with the subjective votes. For the elderly, however, measured TS is 0.5 lower in comparison with PMV.

The difference between young and elderly in thermal comfort (TC) is significant (LME, $P<0.001$ ); Figure 8 . The elderly felt less comfortable during both sessions than the young adults, which is in agreement with TS. Because no significant differences can be detected between the parts of the session (Figure 8b), time effects are excluded for TC as well.

With respect to the preferred temperature, a significant difference (LME, $P<0.01$ ) was found for S1

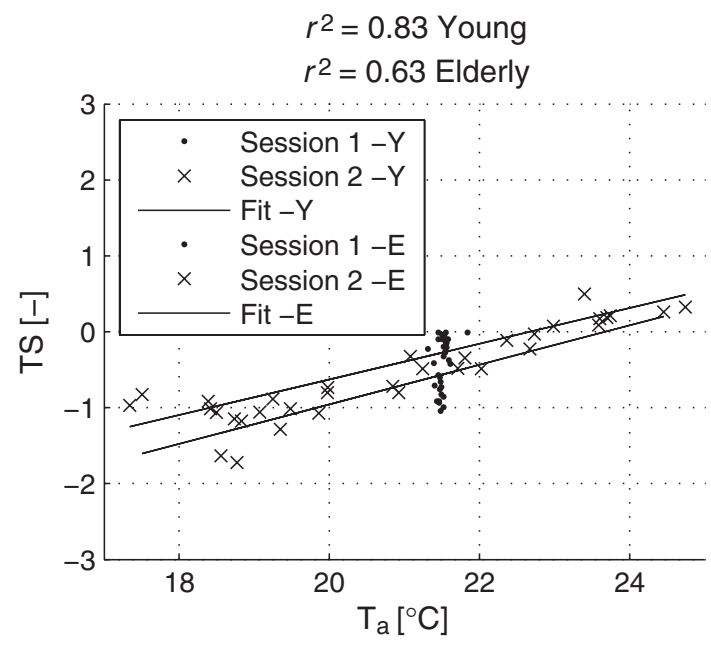

Fig. 7 Linear regression analyses with TS as dependent variable and $T_{\mathrm{a}}$ as independent variable, for both sessions (constant temperature); the elderly preferred a warmer temperature, while the young adults requested no change in temperature. For both young and elderly subjects, mainly skin temperature (mean skin temperature, distal and proximal skin temperature, extent of vasomotion) had a significant $(P<0.05)$ effect on TC.

In Figure 9a,b, the results are represented for one typical young and one typical older adult, respectively, of both experimental sessions ( $\mathrm{S} 1$, left and $\mathrm{S} 2$, right). For both subjects, mean and proximal skin temperatures are clear indicators for thermal sensation (TS). During S1, the older adult is more sensitive for distal skin temperature, which is reflected in TS. Furthermore, lower distal skin temperatures (i.e. vasoconstriction) are reflected in the comfort votes of both subjects, resulting in less comfortable votes. The sudden increase in mean and distal skin temperatures of the older adult during S2 at $t \approx 200$ cannot be explained.

To determine the effects of aging on performance, the data of simulated office tasks were normalized; the
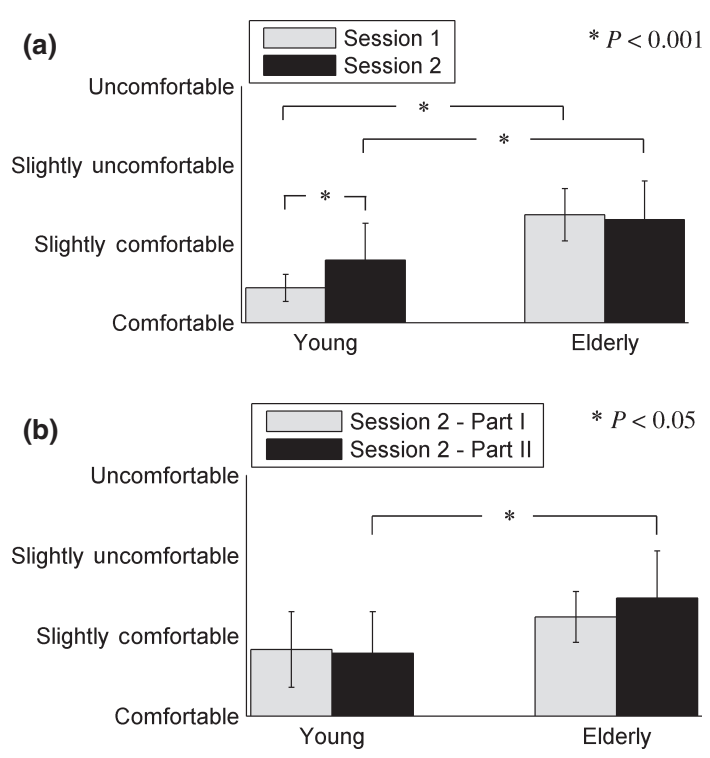

Fig. 8 (a) Averaged thermal comfort votes \pm SD per measurement session (b) Averaged thermal comfort votes; Part 1: first $4 \mathrm{~h}$ of session 2; Part 2: last $4 \mathrm{~h}$ of session 2 


\section{Schellen et al.}
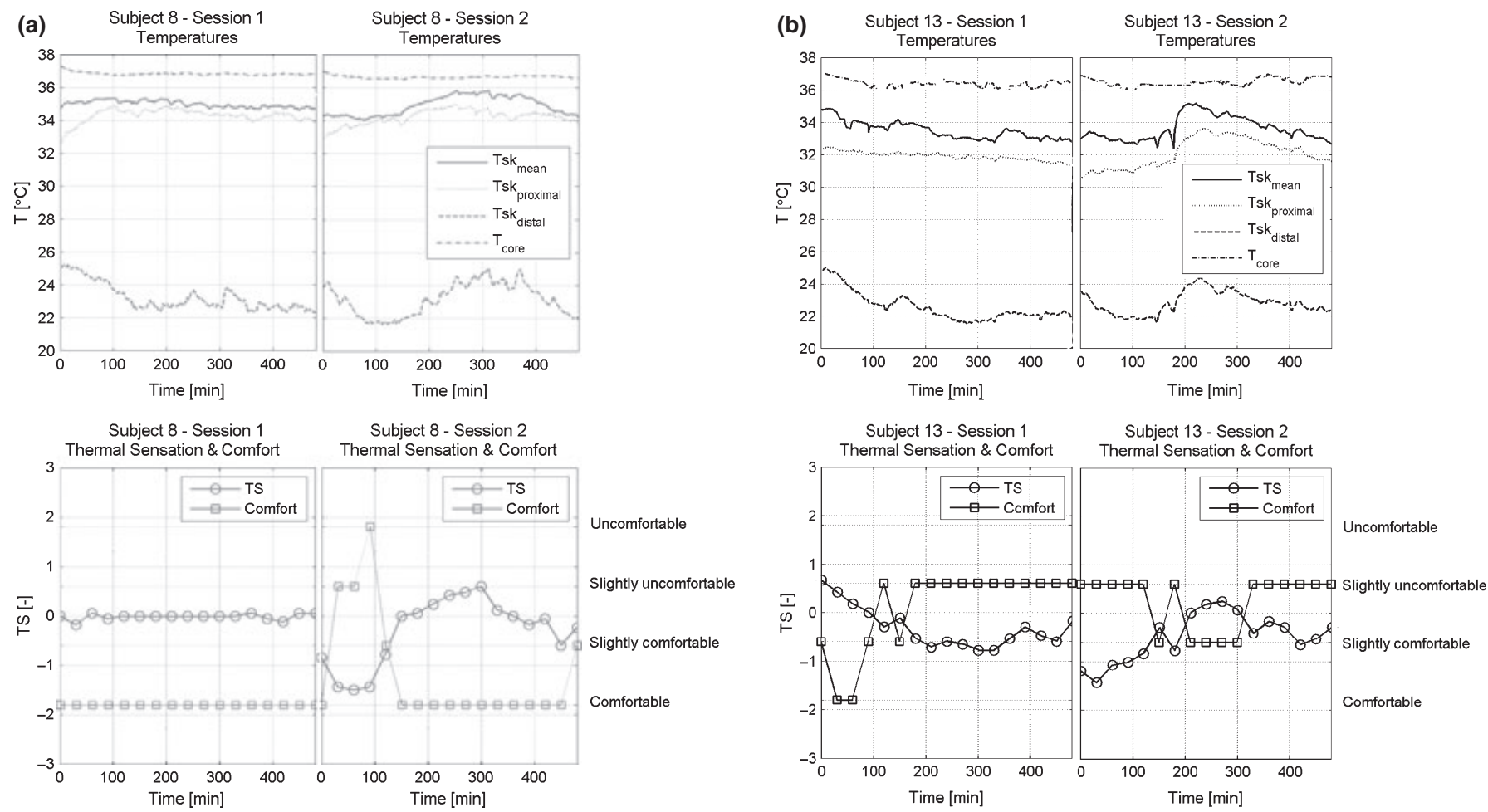

Fig. 9 (a) Individual time plots typical young subject of mean distal and proximal skin temperatures, core temperature, thermal sensation vote and comfort vote for S1 (left) and S2 (right) (b) Individual time plots typical older subject of mean distal and proximal skin temperatures, core temperature, thermal sensation vote and comfort vote for S1 (left) and S2 (right)

maximum score of each subject was equal to $100 \%$, and all other scores of the subject were related to this score. After normalizing the data, the results of the simulated office tasks indicate a significant (LMM, $P<0.05)$ effect of aging on the number of completed additions (Figure 10, left) and the number of correct additions (Figure 10, right). In general, the percentage of completed additions was approximately 15-20\% higher for the young adults in comparison with the elderly; the percentage of correct additions was approximately $5 \%$ higher for the young subjects. Within the groups, no significant differences of the temperature changes were observed. In addition, no significant differences were found between the parts of
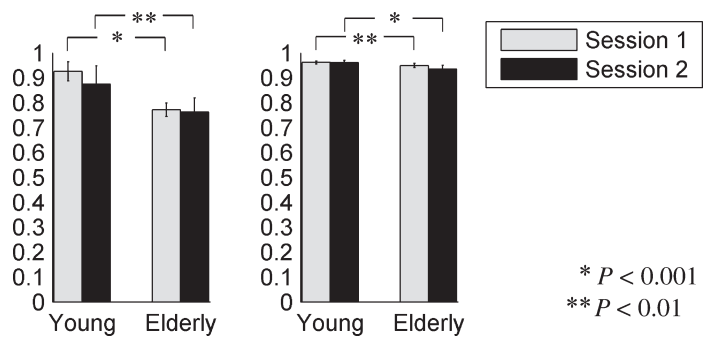

Fig. 10 (left) Average normalized completed additions \pm SD per measurement session (right) Average normalized correct additions \pm SD per measurement session the measurement session; time effects or the type of slope (increasing or decreasing) did not had a significant influence (Figure 11).

(a)

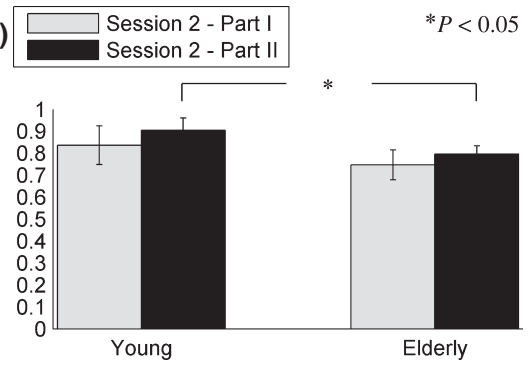

(b)

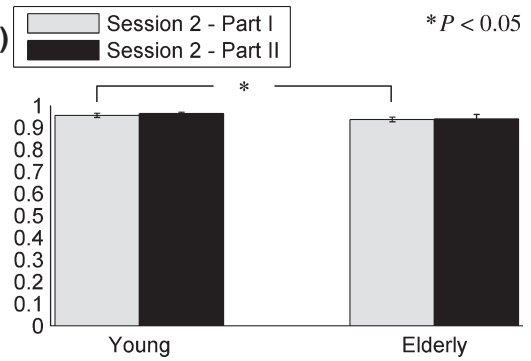

Fig. 11 (a) Average normalized completed additions \pm SD; Part 1: first $4 \mathrm{~h}$ of session 2; Part 2: last $4 \mathrm{~h}$ of session 2 (b) Average normalized correct additions \pm SD; Part 1: first $4 \mathrm{~h}$ of session 2; Part 2: last $4 \mathrm{~h}$ of session 2 


\section{Discussion}

Based on the experimental results for the control situation, it was possible to distinguish between effects of a constant room temperature and transient conditions. The temperature drifts were significantly noticeable for the young subjects (significant differences between session 1 and 2; Figure 6a and 8a). Based on results of the questionnaire, the studied moderate temperature drifts did not result in unacceptable thermal conditions. Furthermore, the results of the individual parts (I and II) show that thermal sensation (TS) and thermal comfort (TC) were not affected by time.

No significant differences in thermal sensation and thermal comfort were observed between the increasing (part I) and decreasing ramp (part II) for both the elderly and younger adults; subjects perceived both ramps equally.

During the stable temperature condition S1, thermal sensation was for both the elderly and young adults related to skin temperature. However, during the moderate temperature drift (S2), TS of the elderly was mainly related to air temperature, while TS of the younger adults was related to skin and air temperature. Thermal comfort was for both conditions (S1 and S2) related to skin temperature.

Fiala (1998) derived a relation between thermal sensation, mean skin temperature, core temperature, and the change in mean skin temperature. In this study, for the elderly subjects, a significant relation was found between air temperature, the extent of vasomotion, and core temperature. For the young adults, a significant relation was found between air temperature, core temperature, and mean skin temperature. The experiments which Fiala used to derive the relation between physiological parameters and thermal sensation were conducted with young subjects (college-age students). Therefore, the results can be compared only with results of the young adults in this study. In this study, no influence of the rate of change in mean skin temperature on thermal sensation of the young adults was observed. Fiala originally included this term to account for rapid (e.g. stepwise) changes in ambient temperature. However, in this study, the temperature changes can be considered as relative slow changes in ambient temperature, which did not caused an immediate change in skin temperature.

Predictions of the thermal sensation obtained with the PMV model showed good agreement with the measurement results for the young adults. For the elderly, conversely, a difference of 0.5 scale units was found between predicted and measured TS. The trends, however, were in good agreement.

The results of the simulated office tasks revealed that aging had a significant negative effect on performance; the average normalized performance was $5-20 \%$ lower for the elderly in comparison with the young adults. Office work normally covers a wide range of different tasks involving a complex set of component skills. Typical tasks include text typing and different types of arithmetical calculations. If these tasks are affected by changes in the indoor environment, it is reasonable to assume that office work in general will be affected similarly.

Importantly, the temperature changes did not affect the productivity, which is in line with results from Seppänen and Fisk (2005) and Tanabe (2006).

The results of the subjective responses, obtained from the experiments carried out within this study, support that the optimum conditions for elderly differ from those of their younger counterparts, which is contrary to ASHRAE (2009). However, more recent studies by, among others, Collins et al. (1981), Hashiguchi et al. (2004), and DeGroot and Kenny (2007) also revealed that the optimum conditions for elderly do differ from the optimum conditions of young adults. Elderly are more vulnerable, compared to young adults, in conditions that differ from neutral, because the efficiency of their cold- and warm-defense mechanisms is declined, and the ability to detect, and therefore respond to, temperature changes is reduced. Furthermore, Poehlman et al. (1994) revealed that their metabolic rate is lower compared to the metabolic rate of younger people owing to a decrease in muscle mass that reduces both the basal and resting metabolic rate.

The thermal sensation of the elderly was in general 0.5 scale units lower than TS of the young adults. The same trend was found for the thermal comfort votes; the elderly felt less comfortable than the young adults. During session S1 with the stable temperature condition $\left(21.5^{\circ} \mathrm{C}\right)$, the elderly preferred a higher temperature, while the young adults requested no change in temperature. The difference in thermal sensation may be explained by a decreased thermoregulatory response (especially the vasoconstrictor response), indicated by the extent of vasomotion measured by the differences in skin temperatures between the young adults and the elderly (Anderson et al., 1996; DeGroot and Kenny, 2007; van Someren, 2007). During the experiments, the elderly were continuously more vasoconstricted (i.e. the skin temperature of the fingertip was mostly lower than the skin temperature of the underarm) in comparison with the young adults.

In this study, no significant correlation was found between the extent of vasomotion or fingertip temperature and thermal sensation parameters, although a relation in literature was found between these parameters (Wang et al., 2007). Wang et al. (2007) found that finger temperature $\left(30^{\circ} \mathrm{C}\right)$ and fingerforearm gradient $\left(0^{\circ} \mathrm{C}\right)$ are significant thresholds for overall thermal sensation. The experiments in this study were conducted under cooler environmental conditions in comparison with the majority of the 
experiments in the study by Wang et al. (2007) ( $T_{\text {neutral }}$ in this study was $21.5^{\circ} \mathrm{C}$ vs. $25.8-27.1^{\circ} \mathrm{C}$ in Wang et al.). Because the hands were not covered during both studies, this resulted in significant lower fingertip temperatures in this study. Based on the results obtained in this study, one could conclude that both fingertip temperature and fingertip-forearm gradient are not applicable as thermal sensation predictors under conditions where the body is nearly continuously in vasoconstriction mode (fingertip-forearm gradient $>0{ }^{\circ} \mathrm{C}$ ). In conditions where the temperature range is larger, it probably can be used as predictor for thermal sensation.

In this study, a significant correlation with the extent of vasomotion was found only for thermal comfort.

It should be mentioned that for the elderly subjects, healthy retired persons were selected who were normotensive and not taking any medications that might alter the cardiovascular or thermoregulatory responses to the temperature changes. The question is whether these healthy elderly subjects are representative for the elderly population because most elderly use medication. For instance, in The Netherlands, in 2008, nearly $73 \%$ of the men in the age of 65 years and older were normotensive and taking medication that might alter the cardiovascular or thermoregulatory responses [CBS, 2009; Website of Statistics Netherlands: www.cbs.nl]. It is possible that the differences in thermal physiology and thermal comfort, between the majority of the elderly population and the young adults, are larger than we report in this study.

\section{Conclusions}

In this study, the differences between young adults and elderly in thermal comfort, productivity, and thermal physiology in response to a moderate temperature drift have been investigated. From the presented results, the following conclusions can be drawn:
Thermal sensation of the elderly is in general 0.5 scale units (on a 7-point thermal sensation scale) lower than thermal sensation of younger adults.

During a constant temperature level and equal clothing level, elderly prefer a higher ambient temperature in comparison with their younger counterparts, which is in line with previous studies.

In this study, the PMV model was capable to predict thermal sensation (TS) of young adults in response to a moderate temperature drift, which is in line with results obtained by previous studies. For elderly, the model is capable to predict the trends in thermal sensation. However, the thermal sensation vote is overestimated with 0.5 scale units; and therefore, for example, the predicted TS corresponds to a sensation equal to neutral, while they will actually feel slightly cool.

Although the subjects were feeling less comfortable during the temperature drift in comparison with a constant temperature level, the conditions did not lead to unacceptable situations, i.e. the studied conditions were not unacceptable uncomfortable. Furthermore, productivity was not negatively influenced by the temperature changes. Therefore, a temperature drift up to $\pm 2 \mathrm{~K} / \mathrm{h}$ in the range of $17-25^{\circ} \mathrm{C}$ is assessed as applicable and will not lead to unacceptable conditions.

\section{Acknowledgements}

This research was funded by Agentschap NL (formerly Senternovem), an agency of the Dutch Ministry of Economic Affairs, under project number EOS LT02003. Their financial contribution is gratefully acknowledged. The authors express their gratitude to the subjects who participated in the experiments. Appreciation is also expressed to the staff of the Laboratory of the Unit Building Physics and Systems (BPS) of Eindhoven University of Technology for their valuable assistance in the design of the climate room and measurement set-up.

\section{References}

Anderson, G.S., Meneilly, G.S. and Mekjavic, I.B. (1996) Passive temperature lability in the elderly, Eur. J. Appl. Physiol., 73, 278-286.

ASHRAE (2004) Thermal Environmental Conditions for Human Occupancy, American Society of Heating, Refrigerating and Air Conditioning Engineers (ASHRAE Standard 55-2004), Atlanta, GA.

ASHRAE (2009) ASHRAE Handbook 2009 Fundamentals, American Society of Heating, Refrigerating and Air-Conditioning Engineers, Atlanta, GA.

Berglund, L.G. and Gonzalez, R.R. (1978a) Occupant acceptability of eight-hour-long temperature ramps in the summer at low and high humidities, ASHRAE Trans., 84, 278-284.

Berglund, L.G. and Gonzalez, R.R. (1978b) Application of acceptable temperatures drifts to built environments as a mode of energy conservation, ASHRAE Trans., 84, 110-121.

Cena, K., Spotila, J.R. and Avery, H.W. (1986) Thermal comfort of the elderly is affected by clothing, activity and psychological adjustment, ASHRAE Trans., 92, 329-342.

Collins, K.J., Exton-Smith, A.N. and Doré, C. (1981) Urban hypothermia: preferred temperature and thermal perception in old age, Br. Med. J., 282, 175-177.

de Dear, R. and Brager, G.S. (1998) Developing an adaptive model of thermal comfort and preference, ASHRAE Trans., 104, 145-167.

de Dear, R. and Brager, G.S. (2001) The adaptive model of thermal comfort and energy conservation in the built environment, Int. J. Biometeorol., 45, 100-108.

de Dear, R.J., Brager, G.S. and Cooper, D. (1997) Developing an Adaptive Model of Thermal Comfort and Preference, Final Report ASHRAE RP-884, American 
Society of Heating, Refrigerating and AirConditioning Engineers, Atlanta.

DeGroot, D.W. and Kenny, W.L. (2007) Impaired defense of core temperature in aged humans during mild cold stress, Am. J. Physiol. Regul. Integr. Comp. Physiol., 292, 103-108.

Durnin, J.V.G.A. and Rahaman, M.M. (1967) The assessment of the amount of fat in the human body from measurements of skinfold thickness. Br. J. Nutr., 21, 681-689.

Fanger, P.O. (1982) Thermal Comfort, Robert E. Krieger, Malabar, FL.

Fanger, P.O. and Langkilde, G. (1975) Interindividual differences in ambient temperatures preferred by seated persons, ASHRAE Trans., 81, 140-147.

Fiala, D. (1998) Dynamsche Simulation des menschlichen Wärmehaushalts und der thermischen behaglichkeit. $\mathrm{PhD}$ thesis, UK, De Montfort University Leicester.

Griffiths, I.D. and McIntyre, D.A. (1974) Sensitivity to temporal variations in thermal conditions, Ergonomics, 17, 499507.

Hardy, J. and Dubois, E.F. (1940) Differences between men and women in their response to heat and cold, Physiology, 26, 389-398.

Hashiguchi, N., Tochihara, Y., Ohnaka, T., Tsuchida, C. and Otsuku, T. (2004) Physiological and subjective responses in the elderly when using floor heating and air conditioning systems, J. Physiol. Anthropol. Appl. Human Sci., 6, 205-213.

Havenith, G. (2001) Temperature regulation and technology, Gerontechnology, 1, 41-49.

Hensen, J.L.M. (1990) Literature review on thermal comfort in transient conditions, Build. Environ., 25, 309-316.

van Hoof, J. (2008) Fort years of Fanger's model of thermal comfort: comfort for all? Indoor Air, 18, 182-201.

van Hoof, J. and Hensen, J.L.M. (2006) Thermal comfort and older adults, Gerontechnology, 4, 223-228.

House, J.R. and Tipton, M.J. (2002) Using skin temperature gradients or skin heat flux measurements to determine thresholds of vasoconstriction and vasodilatation, Eur. J. Appl. Physiol., 88, 141-145.

Howden-Chapman, P., Signal, L. and Crane, J. (1999) Housing and Health in Older People: Ageing in Place, Departments of Public Health and Medicine, Wellington School of Medicine University of Otago.

IEA ECBCS 2007 http://www.ecbcs.org

ISO 7726 (1998) Ergonomics of the Thermal Environment - Instruments for Measuring Physical Quantities, International Standards Organization, Geneva.

ISO 7730 (2005) Ergonomics of the Thermal Environment - Analytical Determination and Interpretation of Thermal Comfort Using Calculation of the PMV and PPD
Indices And Local Thermal Comfort Criteria, International Standards Organization, Geneva.

ISO 9886 (2004) Ergonomics - Evaluation of thermal strain by physiological measurements, International Standards Organization, Geneva

ISO 9920 (1995) Ergonomics of the thermal environment - Estimation of the thermal insulation and evaporative resistance of a clothing ensemble, International Standards Organization, Geneva.

Kildesø, J., Wyon, D.P., Skov, T. and Schneider, T. (1999) Visual analogue scales for detecting changes in symptoms of the sick building syndrome in an intervention study, Scand. J. Work Environ. Health, 25, 361-367.

Knudsen, H.N., de Dear, R.J., Ring, J.W., Li, T.L., Puntener, T.W. and Fanger, P.O. (1989) Thermal Comfort in Passive Solar Buildings. Final Report, CECResearch Project: EN3S-0035-DK(B), Laboratory of Heating and Air Conditioning, Technical University of Denmark.

Kolarik, J., Olesen, B.W. and Toftum, J. (2005) Human thermal comfort in environments with moderately drifting operative temperatures - state of the art and current research, In: Proceedings of Energy Efficient Technologies in Indoor Environment, September 29-30, Gliwice, Poland.

Kolarik, J., Olesen, B.W., Toftum, J. and Mattaralo, L. (2007) Thermal comfort, Perceived Air Quality and Intensity of SBS symptoms during exposure to moderate operative temperature ramps. In: Proceedings of Clima 2007, WellBeing Indoors, Helsinki, Finland, 2007.

Lohman, T.G., Roche, A.F. and Martorell, R. (1988) Anthropometric Standardization Reference Manual. Human Kinetics Book, Champaign, IL.

van Marken Lichtenbelt, W.D., Daamen, H.A.M., Wouters, L., Fronczek, R., Raymann, R.J.E.M., Severens, N.M.W. and van Someren, E.J.W. (2006), Evaluation of wireless determination of skin temperature using iButtons. Physiol. Behav., 88, 489-497.

McCullough, E.A., Jones, B.W. and Tamura, T. (1989) A database for determining the evaporative resistance of clothing, ASHRAE Trans., 95, 316-328.

McCullough, E.A., Olesen, B.W. and Hong, S. (1994) Thermal insulation provided by chairs, ASHRAE Trans., 100, 795-802.

Natsume, K., Ogawa, T., Sugenoya, J., Ohnishi, N. and Imai, K. (1992) Preferred ambient temperature for young and old men in summer and winter, Int. $J$. Biometeorol., 36, 1-4.

Nicol, J.F. and Humphreys, M.A. (2002) Adaptive thermal comfort and sustain- able thermal standards for Buildings, Energy Build., 34, 563-572.

Olesen, B.W. (2004) International standards for the indoor environment, Indoor Air, 14, 18-26.

Olesen, B.W. and Parsons, K.C. (2002) Introduction to thermal comfort standards and to the proposed new version of EN ISO 7730, Energy Build., 34, 537548.

Parsons, K.C. (2003) Human Thermal Environments, Taylor \& Francis, London.

Poehlman, E.T., Arcierio, P. and Goran, M. (1994) Edurance exercise in ageing humans: effects on energy metabolism, Exerc. Sport Sci. Rev., 22, 251-284.

Rohles, F.H. Jr and Johnson, M.A. (1972) Thermal comfort in the elderly, ASHRAE Trans., 78, 131-137.

Rohles, F.H., Laviana, J.E., Wei, R. and Wruck, R. (1985) The human response to temperature drifts in a simulated office environment, ASHRAE Trans., 91, 116123.

Schellen, L., van Marken Lichtenbelt, W., de Wit, M.H., Loomans, M., Frijns, A. and Toftum, J. (2008) Thermal comfort, physiological responses and performance during exposure to a moderate temperature drift. In: Proceedings of the International Conference Indoor Air 2008, Augustus 17-22, Copenhagen, Denmark.

Seppänen, O. and Fisk, W.J. (2005) Indoor climate and productivity, Rehva J, 3, 8-11.

Sessler, D.I. (2003) Skin temperature gradients are a validated measure of fingertip perfusion, Eur. J. Appl. Physiol., 89, 401402.

van Someren, E.W.J. (2007) Thermoregulation and ageing, Am. J. Physiol. Regul. Integr. Comp. Physiol., 292, 99-102.

Tanabe, S. (2006) Indoor temperature, productivity and fatigue in office tasks, In: Proceedings Healthy Buildings 2006, 1, 49-56.

Toftum, J. (2005) Intervention studies with remote measurement of occupant comfort, health and performance, In: Proceedings of International Conference on Environmental Ergonomics, 178-181, Sweden.

Toftum, J., Wyon, D.P., Svanekjaer, H. and Lantner, A. (2005) Remote performance measurement (RPM) - A new, internetbased method for the measurement of occupant performance in office buildings. In: Proceedings of Indoor Air 2005, the 10th International Conference on Indoor Air Quality and Climate, Beijing, China, 2005, pp. 357-361.

Wang, D., Zhang, H., Arens, E. and Huizenga, C. (2007) Observations of upperextremity skin temperature corresponding overall-body thermal sensations and comfort, Build Environ, 42, 3933-3943. 